\title{
CAPÍTULO 32: APLICAÇÃO DO PROGRAMA 5S EM LABORATÓRIO DE CONTROLE DE QUALIDADE DE UM LATICÍNIO
}

\section{CHAPTER 32: APPLICATION OF THE 5S PROGRAM IN A DAIRY QUALITY CONTROL LABORATORY}

\author{
Rubia Viana Batista ${ }^{1}$; Larissa Schlichting. da Silva ${ }^{2}$; Eduarda Molardi Bainy ${ }^{3}$
}

\begin{abstract}
Resumo
O objetivo deste trabalho foi implementar o programa $5 \mathrm{~S}$ em um laboratório de controle de qualidade (CQ) de um laticínio com Serviço de Inspeção Federal (SIF) em Laranjeiras do Sul, Paraná. Inicialmente o programa foi apresentado aos colaboradores do laboratório e definido a composição da equipe e sua integração. Através do trabalho realizado no laboratório foi possível elaborar cronograma e planos de ação para cada senso, junto a responsável pelo CQ do estabelecimento. No fim de cada senso foram realizadas duas auditorias internas para os três primeiros sensos e uma para o quarto e quinto sensos. Foi observada a satisfação pelos resultados obtidos, mudança no comportamento e o sentimento de responsabilidade, equipe e propriedade sobre os sensos. Dentre os benefícios relatados estão a melhoria no ambiente de trabalho, mais limpo e organizado; ambiente mais seguro, evitando-se acidentes; facilidade em encontrar os materiais resultando em aumento da produtividade e redução de desperdícios. No fim do programa foi realizada uma auditoria externa, contemplando todos os sensos, que apresentou resultados satisfatórios na sua implementação. Porém, para continuidade e fortalecimento do programa, é necessário o monitoramento dele, bem como o incentivo e reconhecimento aos colaboradores, que é base da pirâmide da Qualidade Total.
\end{abstract}

Palavras-Chave: gestão da qualidade, cinco sensos, segurança de alimentos.

\begin{abstract}
The objective of this work was to implement the $5 \mathrm{~S}$ program in a quality control laboratory (QC) of a dairy with the Federal Inspection Service (SIF) in Laranjeiras do Sul, Paraná. Initially, the program was presented to the laboratory collaborators and the composition of the team and its integration was defined. Through the work carried out in the laboratory, it was possible to develop a schedule and action plans for each area, together with the person responsible for the establishment's QC. At the end of each sense, two internal audits were carried out for the first three senses and one for the fourth and fifth senses. Satisfaction with the results obtained, changes in behavior and the feeling of responsibility, team and ownership over the senses were observed. Among the reported benefits are the improvement in the work environment, cleaner and more organized; safer environment, avoiding accidents; ease in finding the materials resulting in increased productivity and reduced waste. At the end of the program, an external audit was carried out, covering all the senses, which presented satisfactory results in its implementation. However, to continue and strengthen the program, it is necessary to monitor it, as well as to encourage and recognize employees, basis of the Total Quality pyramid.
\end{abstract}

Keywords: quality management, five senses, food safety.

\footnotetext{
${ }^{1}$ Engenharia de Alimentos, Universidade Federal da Fronteira Sul, rubiavianabatista@ gmail.com

${ }^{2}$ Engenharia de Alimentos, Universidade Federal da Fronteira Sul, 1arischs@ hotmail.com

${ }^{3}$ Doutora em Engenharia de Alimentos, Universidade Federal da Fronteira Sul, eduarda.bainy@uffs.edu.br
} 


\section{Introdução}

Depois da II Guerra Mundial com o Japão destruído, algumas estratégias foram empregadas para reconstruir o país e alavancar as indústrias. A partir daí a gestão da qualidade passou a ser conhecida e utilizada por grandes marcas ao redor do mundo, na busca pela Qualidade Total com ações comportamentais trabalhadas no 5S (Neto et al., 2017). A adoção de programas da qualidade é fundamental para estruturar a gestão organizacional, estabelecer prioridades, organizar, padronizar e realizar melhorias no processo e produtos. Dentre os programas utilizados para obtenção destes resultados está o Programa 5S (Paula et al., 2017).

O programa 5S é conhecido pela simplicidade de seus princípios e por ter como objetivo a promoção da qualidade no ambiente organizacional, renovar os conceitos de organização e produtividade, gerando novos padrões de comportamento. Ele baseia-se em cinco sensos, sendo estes Seiri (Utilização), Seiton (Organização), Seiso (Limpeza), Seiketsu (Padronização/ Saúde e Bem-estar) e Shitsuke (Autodisciplina). Seus resultados são expressivos e verificáveis em curto espaço de tempo e por isso é considerada essencial para ser aplicada junto à programas básicos da qualidade, como as BPF (Andrade, 2015; Souza et al., 2018; Neto et al., 2017). O primeiro senso consiste em eliminar o que é desnecessário no ambiente, o segundo em ordenar local correto aos materiais, o terceiro em realizar limpeza a fundo criando guias para este procedimento, o quarto é responsável por padronizar as boas práticas implementadas pelos três primeiros sensos, enquanto que o último senso consiste no cumprimento e comprometimento das pessoas em todas as etapas (Gobis e Campanatti, 2012; Almeida e Barbosa, 2017; Turbano et al., 2016).

O $1^{\circ}$ Senso de Utilização é fundamentado em tomar conhecimento e classificar os materiais necessários e desnecessários do local, eliminando do laboratório o que não é frequentemente utilizado pela equipe. $\mathrm{O} 2^{\circ}$ Senso de Organização é fundamentado no objetivo de definir local para cada material, de modo que este seja encontrado facilmente. Já o $3^{\circ}$ Senso de Limpeza é baseado na manutenção de um ambiente limpo e organizado, promovendo um ambiente em boas condições sanitárias, seguro e agradável para a equipe de trabalho (Turbano et al, 2016; Costa e Souza, 2017).

O $4^{\circ}$ Senso de Padronização, também como conhecido como o Senso da Saúde e Bemestar, é fundamentado em padronizar as boas práticas implementadas pelos três primeiros sensos, a fim de manter o que já foi conquistado. As ações buscam um ambiente que garanta a saúde física e mental do funcionário, além de padronizar as atividades realizadas por eles (Costa e Souza, 2017). Já o $5^{\circ}$ Senso de Autodisciplina é baseado no cumprimento e comprometimento das pessoas com as etapas já realizadas. A equipe deve compreender e seguir as regras e padrões 
criados, sejam eles escritas ou não, além de garantir que pessoas que passem em seu local de trabalho respeitem elas também. Quando o senso de autodisciplina está consolidado, o programa 5S está consolidado (Habu et al., 1992).

O objetivo do presente trabalho foi implantar o programa $5 \mathrm{~S}$ em um laboratório de controle de qualidade de um laticínio sob inspeção do serviço federal (SIF) localizado em Laranjeiras do Sul/PR, bem como, avaliar e quantificar cada senso na forma de auditoria interna e externa.

\section{Material e Métodos}

A metodologia para implantação do programa $5 \mathrm{~S}$ foi de caráter exploratório e descritivo. O trabalho foi realizado de setembro a novembro de 2018 em um laticínio com Serviço de Inspeção Federal (SIF) do Ministério da Agricultura, Pecuária e Abastecimento (MAPA) localizado em Laranjeiras do Sul. Definiu-se a área piloto como o Laboratório de Controle de Qualidade, por ser um local pequeno, com atividades importantes para a indústria e com necessidade de melhorias.

O trabalho se iniciou com a fundamentação teórica dos sensos por parte do responsável pela implantação deste, seguida da integração com a equipe do laboratório e através da realização do trabalho diário junto a equipe durante aproximadamente um mês. Neste período foi possível conhecer a realidade do trabalho, situação do local, verificar necessidades e particularidades do ambiente, identificando assim, pontos importantes para elaboração dos planos de ação de cada senso.

O cronograma das atividades para a implementação do Programa 5S foi elaborado com a responsável pelo setor do CQ e apresentado na versão final preenchido na Figura $1 . \mathrm{O}^{\circ} \mathrm{S}$ teve duração de três semanas para implementação, sendo que na última semana foi realizada uma auditoria interna, feedback com discussão das não conformidades com equipe e nova oportunidade de adequação dos pontos de melhoria antes da realização da segunda auditoria interna. O $2^{\circ}$ e $3^{\circ}$ Sensos tiveram duração de duas semanas cada para implementação, sendo que na segunda semana foi realizada o mesmo procedimento ( $1^{\mathrm{a}}$ auditoria interna, feedback, tempo para adequação e $2^{\mathrm{a}}$ auditoria interna) como descrito anteriormente para o $1^{\circ} \mathrm{S}$. $\mathrm{O} 4^{\circ} \mathrm{S}$ teve duração de duas semanas para implementação e e $5^{\circ}$ Senso teve duração de uma semana para implementação. Foi realizada apenas auditoria interna para estes dois Sensos, uma vez que não apresentaram grande número de não conformidades. Assim, os sensos tiveram duração de 10 semanas para implementação.

Após definição do cronograma e elaboração de planos de ação para cada senso, foi exposta a proposta de implantação do programa $5 \mathrm{~S}$, o conceito desta ferramenta, abordagem de 
cada senso, os objetivos, ações e benefícios almejados através desta implantação para os colaboradores do Laboratório de CQ.

A equipe $5 \mathrm{~S}$ foi definida, sendo eles, os três analistas do laboratório, a responsável pela implantação do programa e a responsável pelo CQ. Foram realizados registros fotográficos da situação atual do laboratório, para posteriormente fazer comparação entre antes e depois das atividades propostas pelos planos de ação.

Figura 1. Cronograma do plano de ação das atividades do programa 5S.

\begin{tabular}{|l|l|l|l|l|}
\hline \multicolumn{5}{|l|}{ Cronograma - Programa } \\
\hline
\end{tabular}

Fonte: Própria (2018).

A cada início de senso, realizava-se uma reunião com a equipe sobre o senso, a proposta dele e as atividades relacionadas no plano de ação elaborado. As ações compreendidas nos planos foram realizadas pela equipe do laboratório e pela responsável pela implantação do programa, sendo adequada conforme fluxo de trabalho do laboratório. Em cada plano de ação foram apresentadas as ações a serem realizadas pela equipe do $5 \mathrm{~S}$, os integrantes da equipe, e espaços destinados ao registro de conclusão da atividade.

As auditorias internas foram realizadas no fim da implementação de cada senso pela responsável do programa e pela responsável pelo CQ da empresa. As fichas de avaliação para as auditorias internas foram elaboradas baseadas nos planos de ação de cada senso, levando em consideração particularidades do ambiente de trabalho em questão, sendo estabelecidas notas para cada item, sendo 1 para ruim, 2 para regular, 3 para bom, 4 para ótimo e NA para não aplicável. A nota de corte 3 foi estabelecida para aprovação para seguir para próximo senso. 
Quando necessário, foi orientado que o auditor anotasse observações para que estas fossem discutidas com a equipe 5S e implementadas antes de seguir para o próximo senso.

No fim do cronograma das atividades foi realizado uma auditoria interna pela responsável pelo programa e pela responsável pelo CQ. Na quarta semana de novembro de 2018 foi realizada uma autoria externa no Laboratório de CQ, por uma Engenheira de Alimentos com experiência no Programa 5S e externa ao laticínio. Essa auditoria final contemplou todos os 5 sensos. Nesta auditoria obteve-se uma nota média para cada senso, sendo possível comparar com as notas anteriores. O objetivo da auditoria final externa foi possuir um parâmetro geral dos sensos realizados e obter uma visão externa com ideias para melhoria contínua do $5 \mathrm{~S}$.

\section{Resultados e Discussão \\ $1^{\circ}$ Senso - Utilização}

$\mathrm{Na}$ primeira etapa do programa $5 \mathrm{~S}$, iniciando pelo senso de utilização, foi realizada reunião com a equipe do laboratório para explicar o propósito do senso e de suas ações. As atividades do plano de ação para o senso de utilização foram realizadas exclusivamente pela equipe de analistas do laboratório. Nesta etapa foi retirado materiais identificados como desnecessários ou que não pertenciam àquele ambiente de trabalho, materiais quebrados e em excesso, reagentes vencidos, que acabam ocupando espaço e além de não ser utilizado. A equipe ficou responsável em determinar o estoque suficiente dentro do senso de utilização e que deveriam estar no laboratório em quantidade suficiente para o trabalho de no mínimo uma semana.

Realizadas as ações propostas pelo plano de ação, fez-se a primeira auditoria interna com a responsável pela implantação do programa e a responsável pelo setor da qualidade do estabelecimento. Foram realizadas duas auditorias internas em momentos distintos apresentadas na Figura 2. 
Figura 2. Primeira e segunda auditoria interna do $1^{\circ}$ senso - Utilização.

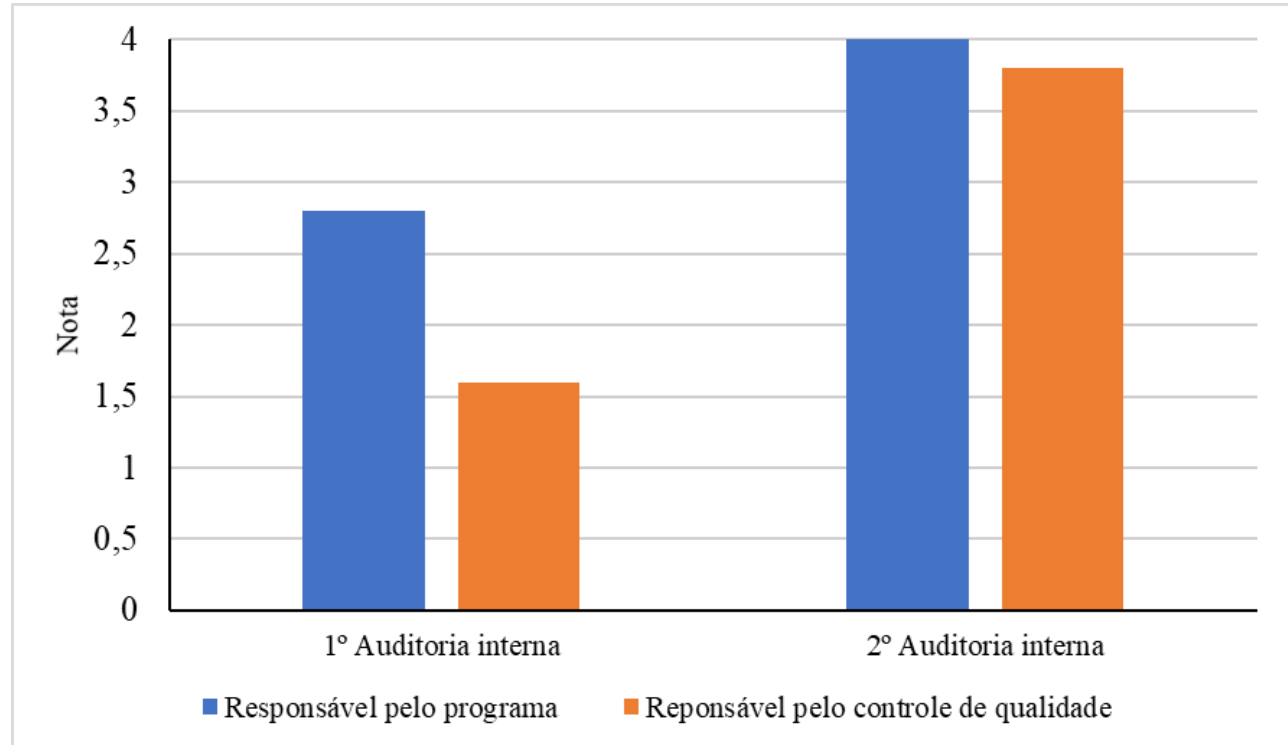

Fonte: Própria (2018).

As médias das notas obtidas para o senso de utilização na primeira auditoria foram respectivamente 2,8, ficando entre regular e bom, e 1,6 ficando entre ruim a regular. As notas não demonstraram um bom desempenho do senso de utilização, o que já era o esperado uma vez que se trata de um programa novo e equipe estava se habituando ao objetivo, criação de novos hábitos e proposta dele.

As auditorias foram realizadas em turnos diferentes pelo responsável do programa e responsável do CQ. Observou-se que após a auditoria da manhã feita pela responsável pelo CQ, a equipe atendesse as não conformidades imediatamente. Com isso, alguns itens não foram identificados na auditoria do período da tarde pela responsável pelo 5S. Consequentemente, as notas finais da responsável pelo $5 \mathrm{~S}$ foram superiores às notas da responsável pelo $\mathrm{CQ}$.

As não conformidades observadas nas auditorias sobre este senso foram a presença de itens pessoais no laboratório, presença de galões que são utilizados pelo setor de fabricação, excesso de rascunhos pelas bancadas, presença de alguns materiais em desuso sobre bancadas e geladeira. Como as notas das auditorias foram menores do que 3 , foi passado a equipe as não conformidades encontradas, solicitando que estas fossem atendidas e com isso todos os itens propostos no plano de ação foram concluídos para realizar uma segunda auditoria.

É possível observar na segunda auditoria que as notas referentes às ações do $1^{\circ}$ senso melhoraram consideravelmente, ficando agora entre bom e ótimo. Isso demonstra que com o decorrer do tempo e com adaptação aos novos hábitos implementados na rotina de laboratório, a equipe amadureceu as ideias propostas e passou a mudar seu comportamento alinhando este ao senso de utilização do programa. 


\section{$2^{\circ}$ Senso - Organização}

As atividades propostas no plano de ação do $2^{\circ}$ senso foram realizadas na grande maioria pela responsável pela implantação do programa, devido a equipe não dispor de tempo para realizar ações como etiquetar e demarcar as áreas, por exemplo, e por isso foram os responsáveis secundários pelas atividades. Foi realizada demarcação com fita vermelha de todos os equipamentos, reagentes categorizando pelo tipo de análise, além da área do escritório destinada para organização dos registros.

Também foi providenciado um organizador de documentos, etiquetas para identificação de cada área, reagente e material e pastas para não amassar os documentos. Na bancada de análises foi removido papel perflex e substituído por papel contact branco, forrado com plástico transparente, que permitiu facilitar a limpeza da bancada, promovendo assim ambiente mais agradável.

Os reagentes foram organizados em fileiras, dispostos de maneira ordenada por tipo de análise, e apenas em quantidade suficiente para aproximadamente uma semana, evitando acúmulo de estoque exagerado. As demais áreas também foram demarcas e identificadas, tais como os locais de armazenamento dos materiais de limpeza e materiais de análise, assim como as áreas de análises das coletas individuais dos produtores, espaço para preenchimento de planilhas e as prateleiras da geladeira.

Foi realizada conscientização da equipe para manutenção da ordem e organização do laboratório. Assim como conscientização dos colaboradores de outros setores que eventualmente utilizam o laboratório. Além disso, todas as tomadas do laboratório foram identificadas quanto à sua voltagem. No fim das atividades propostas pelo senso de organização, realizou-se auditoria interna, sendo que as notas médias da primeira e segunda auditorias estão demonstradas no Figura 3. 
Figura 3. Primeira e segunda auditoria interna do $2^{\circ}$ senso - Organização.

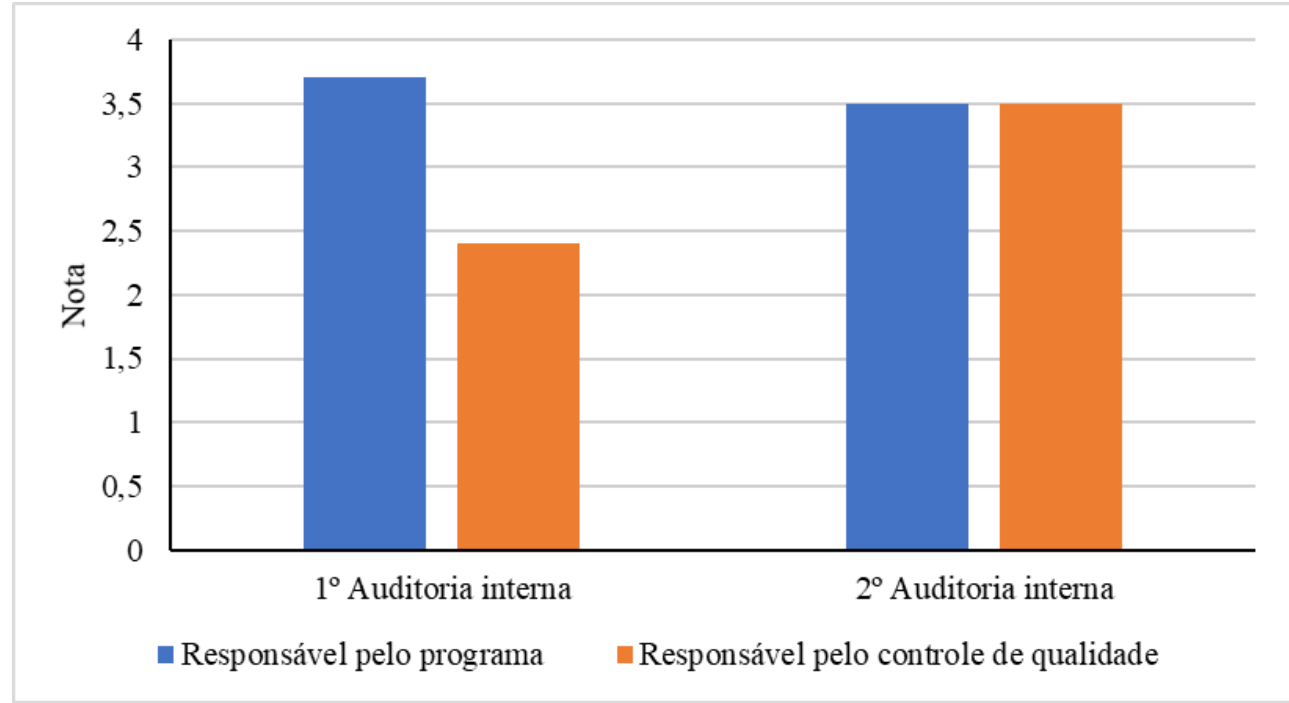

Fonte: Própria (2018).

Nesta auditoria foi observado alguns locais não estavam identificados, além da desordem de algumas prateleiras e a presença de itens pessoais no laboratório. As notas nesta auditoria ficaram entre regular e bom, sendo estas satisfatórias (acima de 3). Comparando com as notas da primeira auditoria do $1^{\circ}$ senso, houve uma evolução da implementação do programa 5S na área piloto. Foram discutidas com a equipe as não conformidades, a fim de conscientizálos sobre a importância em manter a ordem e respeitá-la, bem como exigir o mesmo dos colegas de outros setores. Na segunda auditoria inteira, as notas foram 3,5 (Figura 2), entre bom e ótimo na escala de pontuação, resultado que demonstra evolução da equipe quando comparada à primeira auditoria do senso.

No início do programa identificaram a dificuldade de comunicação entre os colaboradores e com isso, foi solicitado um quadro de lousa, para que ali fosse anotado recados pertinentes ao programa e às atividades do laboratório. Esta estratégia de comunicação foi assertiva, promoveu interesse pelos recados anotados e facilitou a comunicação, uma vez que eles liam quando pudessem, assim suas atividades também não eram prejudicadas.

\section{$3^{\circ}$ Senso - Limpeza}

Para o senso de limpeza, inicialmente foi explicado à equipe para que estabelecessem um dia da semana para limpeza, onde seria realizada uma limpeza mais fina em prateleiras e bancadas, sendo determinado pela equipe o domingo. As demais atividades rotineiras de lavagem de vidrarias, caixas, baldes, bancadas, troca de lixo e descarte do resíduo orgânico seria diariamente, ao fim do expediente ou sempre que necessário. 
Para padronizar essas atividades, foi elaborado um guia rápido com os itens que necessitavam de limpeza, a frequência e o procedimento desta. A finalidade do guia foi reforçar estes pontos para equipe, mas também como maneira de orientar outras pessoas que venham realizar a tarefa no laboratório, como em casos de admissão de novo analista.

Avisos também foram fixados em locais estratégicos e de fácil visualização a fim de orientar e reforçar as ações para a própria equipe, mas também para colaboradores de outros setores que tem acesso ao laboratório. Foi orientado também que a equipe criasse o hábito de manter o ambiente limpo e organizado, evitando assim que no final do expediente precisassem de mais tempo para isto.

As atividades propostas no plano de ação do senso de limpeza foram responsabilidade, em sua grande maioria, pela equipe do laboratório e a responsável pela implantação do programa. À medida que se verificavam não conformidades, até mesmo relacionada aos $1^{\circ}$ e $2^{\circ}$ sensos, a equipe foi orientada para tomar as devidas providências. A primeira e segunda auditoria interna para o senso de limpeza tem suas notas apesentadas na Figura 4.

Figura 4. Primeira e segunda auditoria interna do $3^{\circ}$ senso - Limpeza.

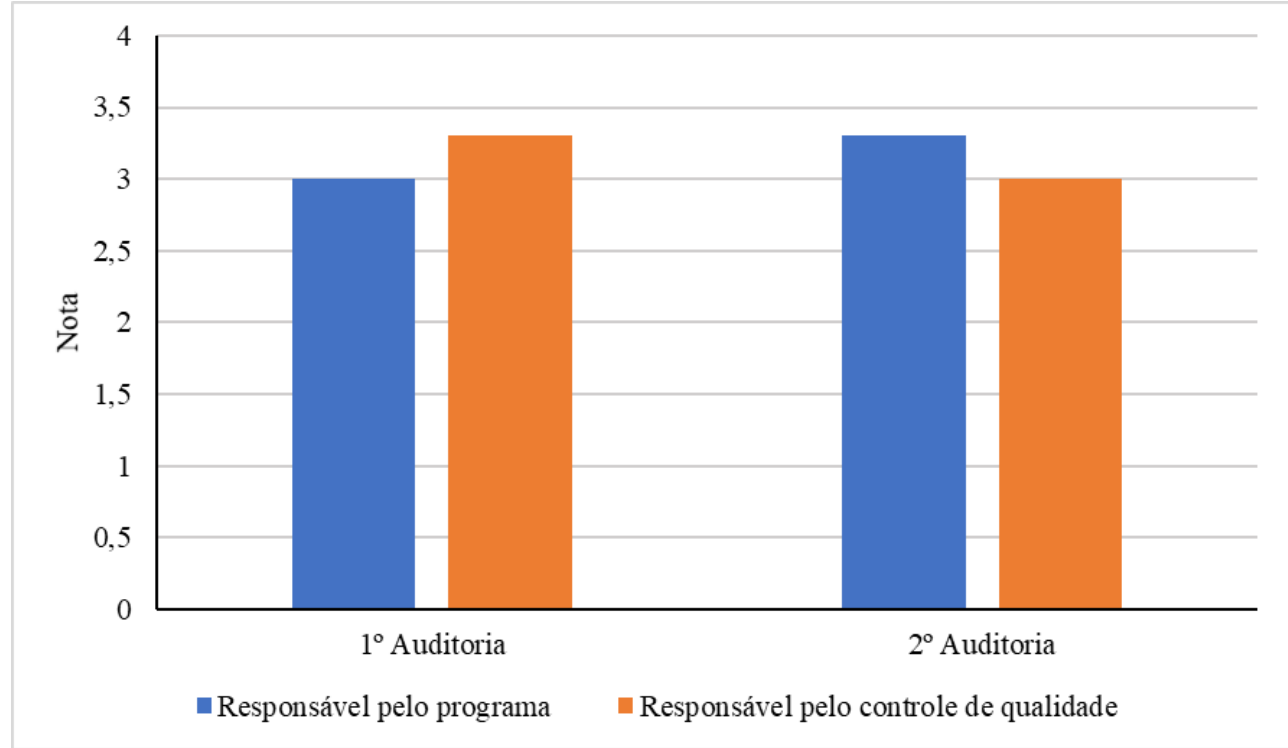

Fonte: Própria (2018).

As notas ficaram em torno de 3 que representa bom. Não conformidades foram feitas quanto ao descumprimento da frequência de limpeza dos itens solicitados, não havia disponibilidade de material de limpeza para realizar a tarefa e não havia manutenção do ambiente limpo e em ordem. Estas não conformidades foram discutidas com a equipe e orientadas sobre a importância e benefícios obtidos com o cumprimento das atividades presente no plano de ação. 
A segunda auditoria interna do senso (Figura 3) apresentou as mesmas notas obtidas após algum tempo trabalhado este senso com a equipe, permanecendo como bom. Durante toda a implementação do programa o senso de limpeza foi que mais apresentou não conformidades e descumprimento ao combinado, sendo que entre a principal justificativa para tal estava a falta de tempo devido elevado fluxo de carregamentos no laticínio.

Novamente foi observado itens sujos pelas bancadas, frequência da troca algodão do suporte das pipetas não atendido, presença de sujidades do dia anterior, lixeiras abertas, entre outras não conformidade. Este fato demonstra que este senso deve ser trabalhado com a equipe com mais atenção.

\section{$4^{\circ}$ Senso - Padronização/Saúde e Bem-estar}

As ações propostas no plano de ação do senso de padronização eram basicamente elaboração de procedimentos e guias rápidos para as atividades realizadas no laboratório, como organização de amostras na geladeira, procedimentos curtos para uso dos equipamentos e para preenchimento de planilhas. Além de orientação aos colaboradores quanto às Boas Práticas de Laboratório a fim de evitar-se acidentes no local. A intenção destas ações foi promover através do estabelecimento de padrões, um ambiente agradável e seguro para o colaborador, livre de estresses causados por pela falta de comunicação ou desencontro dela.

Um dos padrões estabelecidos foi a organização das amostras na geladeira, as quais devem ser dispostas de baixo para cima, sabendo desta forma que as primeiras a serem colocadas, seriam as primeiras a serem analisadas. Caso um novo analista comece a trabalhar no laboratório, saberá como dispor amostras na geladeira devido identificação com o padrão estabelecido. O guia rápido da limpeza fixado em local estratégico e de fácil visualização, com os itens, frequência e procedimento determinados junto com a equipe do laboratório, bem como a identificação para organização padrão das amostras de leite dentro da geladeira.

Para o senso de padronização e autodisciplina foi realizada apenas uma auditoria interna, uma vez que não foi um senso que apresentou grande número de não conformidade. As notas das auditorias estão apresentadas na Figura 5.

[508] 
Figura 5. Auditoria interna do $4^{\circ}$ senso - Padronização.

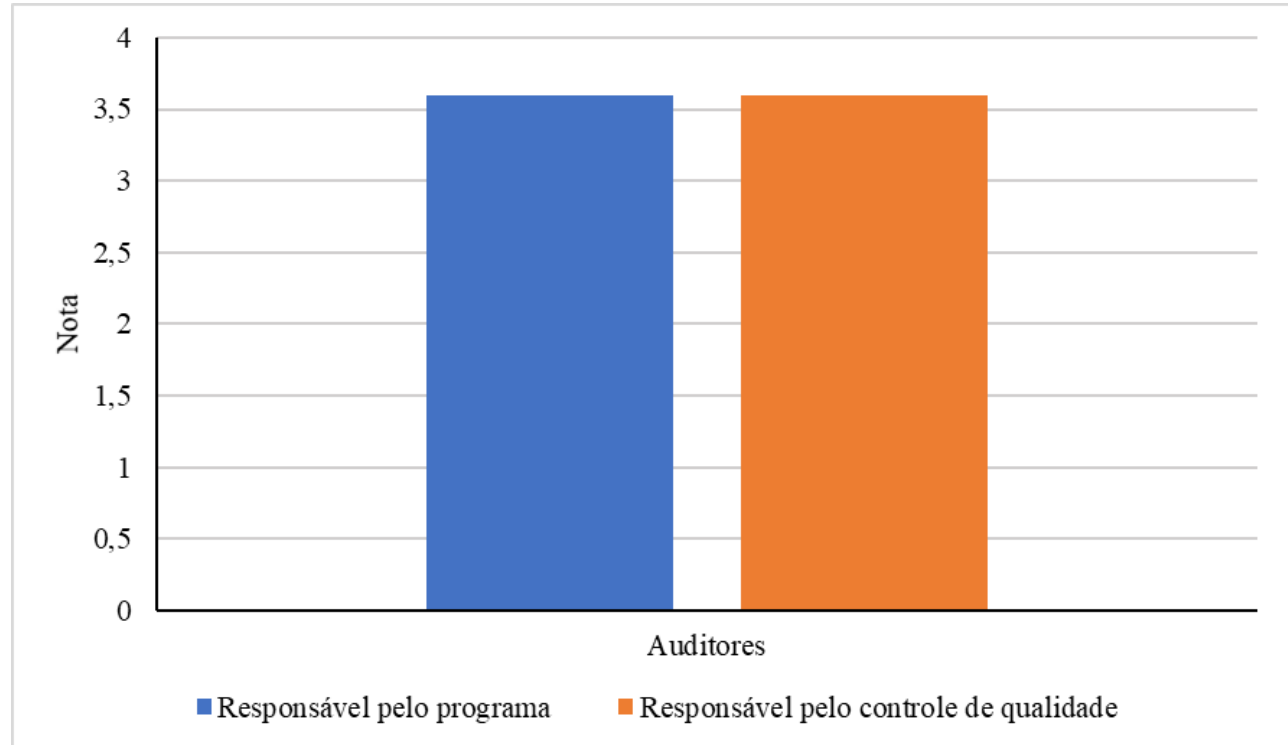

Fonte: Própria (2018).

Ambas as notas foram 3,6, ficando entre bom e ótimo. Este resultado foi satisfatório, considerando a importância deste senso para validação do restante. A não conformidade observada no $4^{\circ}$ senso foi que alguns guias de trabalho não estavam sendo cumpridos pela equipe, o que foi orientado para que passassem a cumpri-los.

Foi observado que os três primeiros sensos foram os mais densos e que exigiram mais tempo para serem trabalhados e estabelecimento de novos hábitos que levam no mínimo 3 semanas para serem criados pelas pessoas. Porém, os dois últimos sensos, de padronização e autodisciplina são os mais complexos de serem consolidados, levando em consideração que exige a real mudança organizacional e no comportamento da equipe, além da manutenção do interesse, motivação pelo programa e autodisciplina de cada colaborador.

\section{$5^{\circ}$ Senso - Autodisciplina}

O último senso é o mais desafiador para ser validado. Foi trabalhado com a equipe por meio de reuniões, aplicação de 'testes orais' utilizando pontuação, a fim de incentivar o colaborador a se apropriar do conceito do programa e dos cinco sensos.

Nos testes foram questionados os conceitos básicos de cada senso, os benefícios percebidos no ambiente de trabalho com a implementação de cada um, principais dificuldades encontradas e o que poderia ser feito a respeito. Assim foi possível obter informações sobre as percepções e feedback de cada colaborador. Também foi instigado a equipe sobre qual seria o próximo passo com o fim do cronograma de implementação do $5 \mathrm{~S}$. 
Os principais benefícios citados pelos colaboradores com a implementação do Programa 5S foram: 1) Melhora no ambiente de trabalho, mais limpo e organizado; 2) Ambiente mais seguro, de maneira que se previne acidentes de trabalho; 3) Evita-se desperdícios, com menor estocagem de material no laboratório e utilização dos materiais mais antigos antes; 4) Redução de tempo e maior produtividade na execução das análises, pela facilidade em encontrar os materiais que foram organizados no $1^{\circ} \mathrm{S}$.

A motivação e a responsabilidade sobre o programa foram observadas pela equipe que se tornou proativa e autônoma para manutenção dos primeiros sensos, como por exemplo substituição das etiquetas do laboratório, adotando um padrão para tamanho e letra de impressão, e identificaram vários outros itens que não haviam sido previamente identificados.

Foi possível observar também que na equipe do laboratório, um colaborador se destacou quanto à motivação com o programa. Foi nítido a influência deste com o restante da equipe, além de motivar os colaboradores externos que tem acesso ao laboratório e até mesmo a responsável pelo controle de qualidade do estabelecimento, que demonstraram mudança no comportamento conforme a implementação do $5 \mathrm{~S}$.

A auditoria do $5^{\circ}$ senso foi realizada pela responsável pelo $5 \mathrm{~S}$ e pela responsável pelo controle de qualidade do estabelecimento. As notas estão demonstradas na Figura 6.

Figura 6. Auditoria interna do $5^{\circ}$ senso - Autodisciplina.

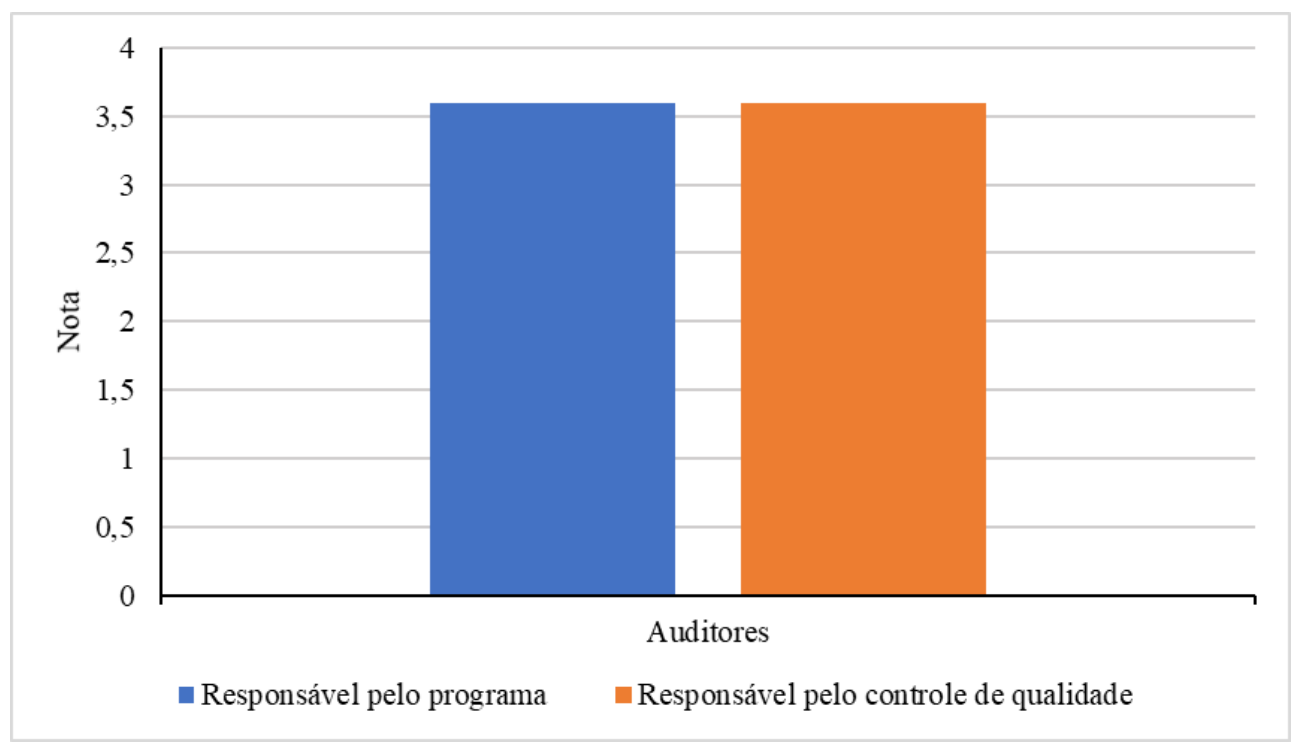

Fonte: Própria (2018).

Ambas as notas da auditoria foram 3,6, estando entre bom e ótimo. A nota de corte estabelecida no início do programa era $3, \log$ o resultado foi considerado satisfatório pois demonstrou comprometimento, apropriação, e conhecimento da equipe com relação ao programa 5S. 
Com o 5S é possível tornar o local de trabalho um ambiente seguro, agradável e motivador para os funcionários, além de modificar a relação destes com o seu trabalho, contribuindo assim para o aumento do moral, promovendo sentimento de propriedade e orgulho (Almeida e Barbosa, 2017). A ferramenta contribuiu para importantes pilares da Qualidade Total, como a produtividade, custos, segurança, entrega e moral.

\section{Auditoria Externa}

Como proposto no cronograma de implantação do programa 5S, na última semana de novembro de 2018 após 10 semanas de implementação do 5S, realizou-se a auditoria final externa por uma Engenheira de Alimentos com experiência na área, acompanhada pela responsável pelo programa e pela responsável pelo CQ do estabelecimento. As notas da auditoria externa para cada senso estão apresentadas Figura 7, onde é possível notar que todas as notas ficaram na faixa de 3 e 4 , que representa bom e ótimo, representando resultado positivo quanto ao trabalho realizado pela equipe no laboratório.

Figura 7. Notas da auditoria final externa.

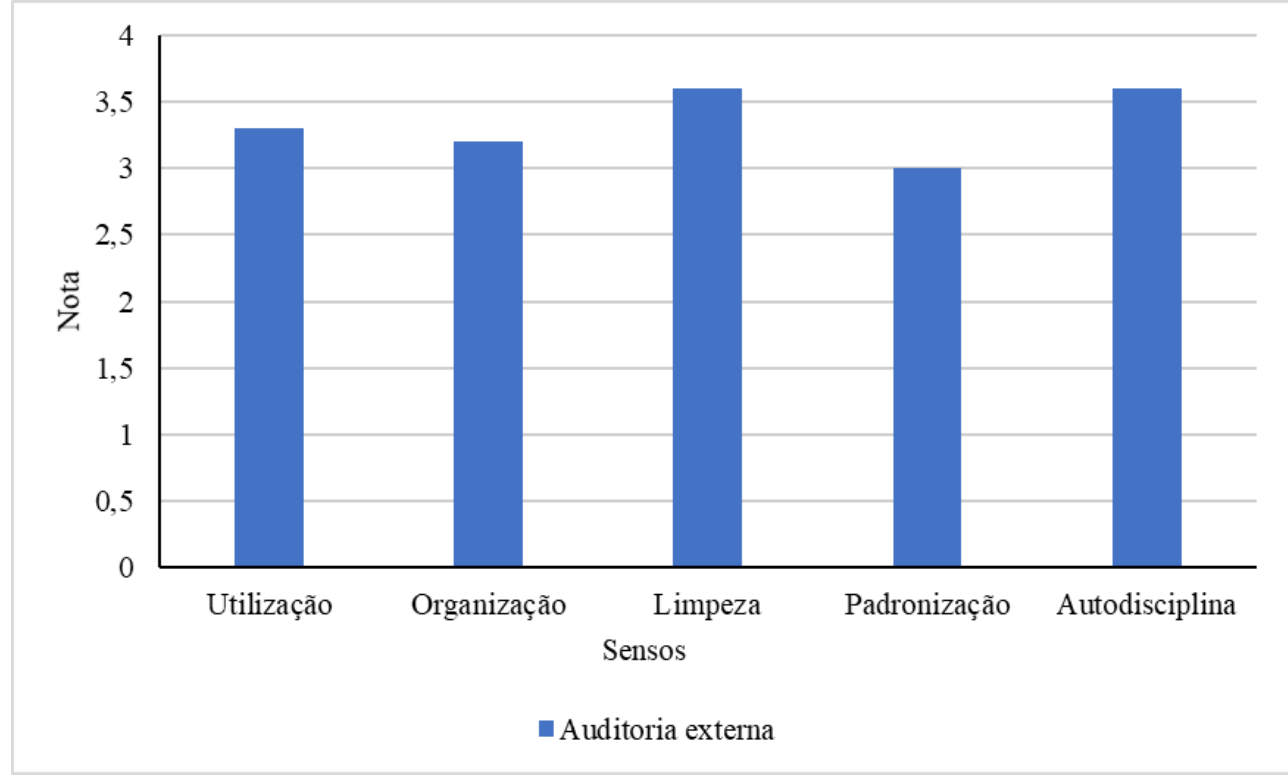

Fonte: Própria (2018).

Dentre as não conformidades levantadas, pode citar a falta de identificação de alguns itens, ajuste de etiquetas de equipamentos e uso de pallets para os baldes em contato com o chão. Foi sugerido também elaboração de procedimento para os crioscópios do laboratório, elaboração de registro de limpeza diário, registro das reuniões relacionadas ao programa, bem como uma ficha para treinamento de novos analistas do laboratório. A responsável pelo CQ e a equipe do $5 \mathrm{~S}$ relatou que o programa promoveu a melhoria considerável do ambiente de trabalho, satisfação da equipe com o trabalho, diminuição de stress decorrente da desorganização, maior segurança no trabalho e produtividade. 


\section{Conclusões}

A implantação do programa 5S inicialmente apresentou certas dificuldades relacionadas à interação e interesse da equipe do laboratório com o programa e ações propostas. Com o decorrer da implementação do $5 \mathrm{~S}$ foram empregados outros recursos e meio de comunicação para que a equipe compreendesse a importância e se apropriassem das atividades. Diversos momentos demonstraram que a estratégia utilizada estava funcionando e a equipe se sentia responsável pelo programa. Foi possível observar os novos hábitos adotados pela equipe, diminuição de reclamações do setor, satisfação da equipe, diminuição de stress, maior segurança no trabalho e produtividade.

Com o término do programa foi possível observar a mudança que o programa promoveu no laboratório de controle de qualidade do estabelecimento, perceptível na responsabilidade da equipe com o programa, orientação a outros colaboradores quanto ao respeito pela ordem e organização do local, realizada pela própria equipe do laboratório. Foi possível observar o desenvolvimento de importantes pilares da Qualidade Total, como a produtividade, custos, segurança, entrega e moral. No entanto, para a continuação do programa e sobrevivência dele se faz necessário o monitoramento dele para manter o Programa $5 \mathrm{~S}$ vivo, como também incentivo e reconhecimento por parte dos superiores, fortalecendo assim a base da pirâmide, que é o moral dos funcionários.

\section{Referências}

ALMEIDA, F. N. C. Implantação da metodologia 5S nos laboratórios de pesquisa de uma universidade pública. Orientador: Danilo Hisano Barbosa. 2017. 31 f. Trabalho de Conclusão de Curso (Graduação em Engenharia de Produção), Universidade Estadual de Maringá, Maringá, 2017.

ANDRADE, R. L. Análise do ambiente organizacional para implantação do sistema $5 \mathrm{~S}$ no almoxarifado de uma empresa maranhense. Trabalho de Conclusão de Curso (Graduação em Administração), Universidade Federal do Maranhão, São Luís, 2015.

CAMPOS, V. F. TQC: Controle de Qualidade Total (no estilo japonês). Belo Horizonte, MG: Fundação Christiano Ottoni, 2014.

COSTA, B. W. C. e SOUZA, F. A. Análise do programa 5S e das aplicações da ferramenta da qualidade por alunos de engenharia. Anais do IX Simpósio de Engenharia de Produção de Sergipe, 2017.

GOBIS, M. A. e CAMPANATTI, R. Os benefícios da aplicação de ferramentas de gestão de qualidade dentro das indústrias do setor alimentício. Revista Hórus, v. 7, n. 1, p. 26-40, 2012. 
HABU, N.; KOIZUMI, Y.; OHMORI, Y. Implementação do 5S na prática. Editora Icea, Campinas/SP, 1992.

NETO, O. P. C.; PINHEIRO, L. G. P. e OLIVEIRA, A. S. Análise de feitos da implantação do programa 5S em distintos segmentos. Produção em Foco, v. 7, n. 2, p. 290-307, 2017.

PAULA, L. N.; ALVES, A. R. e NANTES, E. A. S. A importância do controle de qualidade em indústria do segmento alimentício. Conhecimento online, v. 2, 2017.

SOUZA, B. C.; PINTO, G. A.; PAULA, P. P.; LOBO, R. J. e SOUZA, F. V. P. Implantação do programa 5S através da metodologia DMAIC. Braziliam Journal of Developement, v. 4, n. 5, p. 2163-217, 2018.

TURBANO, V. S.; ANDRADE, C. T. A. A.; BEZERRA, F. M. e SALES, J. P. Aplicação do programa $5 \mathrm{~S}$ em uma empresa de artefatos de couro da região metropolitana do Cariri. XXXVI Encontro Nacional de Engenharia de Produção, João Pessoa/PB, 2016. 